\title{
Online Teaching During COVID-19: Perception of Medical Undergraduate Students
}

\author{
Anjali Verma $^{1} \cdot$ Surender Verma ${ }^{2,3}\left(\right.$ D $~ \cdot$ Pradeep Garg $^{2} \cdot$ Rajesh Godara ${ }^{2}$
}

Received: 4 June 2020 / Accepted: 18 June 2020 / Published online: 27 June 2020

(C) Association of Surgeons of India 2020

Dear Editor in Chief
Indian Journal of Surgery,

The impact of COVID-19 pandemic is profound not only on physical health but also on routine teaching worldwide as a result of containment measures being taken for its prevention. Medical education is also affected as a result of changes in current teaching methodology due to cancellation of classical "classroom teaching" $[1,2]$. As there is uncertainty about duration of this pandemic and social distancing measures are needed for long, hence, education of future doctors requires intense and prompt attention [3]. Previous studies have shown postgraduate students' perspective on these online classes [4,5] but undergraduate students' perception is missing and even more important. Postgraduates are less in number and they learn during their duties and on rounds whereas these aspects are lacking in undergraduates who are entirely dependent on online teaching during this pandemic.

An online teaching program was started in our tertiary care teaching institute from 22 April 2020 as per already circulated roster of didactic lectures which were conducted every day in classroom setting. Google Meet was used to take the classes which included whole class of 200 students and each class was for time period of $60 \mathrm{~min}$. After 1 month of program, perceptions of fourth year students were asked online using a questionnaire and they were asked to write feedback. This session was being recorded and later analysed. Feedback responses were received from 130 participants. Almost all of the students found the online sessions to be relevant and tailored

Surender Verma

drsurn@gmail.com

Pediatrics, PGIMS, Rohtak, Haryana, India

General Surgery, PGIMS, Rohtak, India

3 Rohtak, India to the students' learning needs $(n=127(99 \%))$. Seventy-five $(57 \%)$ students felt these classes safe, comfortable and enjoyable. Still many of them (120 (92\%)) felt these classes as good utilization of time and reading on those topics decreased their stress about COVID-19.

Common issues like teachers not being technology friendly, lack of interactive teaching, easy distraction and technical issues were highlighted by some of them. Half of them (67 $(51 \%)$ ) felt their internal assessment could not be done properly which used to motivate them to summarize the whole topic. All of them feel ward teaching, practical and clinical teaching is grossly deficient. Integrated teaching which is a part of MCI curriculum involving both clinical and paraclinical aspects is also missing.

Sixty-two (47\%) students want online classes to be made part of their curriculum after COVID. Out of them, 15 want their theory lectures to be replaced by online classes whereas 3 want these classes in addition to routine theory classes. Students gave suggestions to take attendance using online method even in conventional teaching as it saves a lot of time. In addition, they want practical demonstration classes using technology during this pandemic.

Although classical "classroom teaching" is not possible to replicate through online teaching, still it is a cheap and feasible method which helps to gain knowledge, maintaining routine and improving morale of teachers and students. We propose several innovative solutions including the flipped classroom model with previously providing online material, online practice questions, procedures and examination videos and assessment should be done in the form of MCQ/scenario-based questionnaires.

Acknowledgements Dr. Sukhdev Chandla, Professor Incharge IT and Telemedicine, PGIMS, Rohtak, for facilitating online teaching.

\section{Compliance with Ethical Standards}

Conflict of Interest The authors declare that they have no conflict of interest. 


\section{References}

1. Chick RC, Clifton GT, Peace KM, Propper BW, Hale DF, Alseidi AA, Vreeland TJ (2020) Using technology to maintain the education of residents during the COVID-19 pandemic. J Surg Educ 77:729732. https://doi.org/10.1016/j.jsurg.2020.03.018

2. Ferrel MN, Ryan JJ (2020) The impact of COVID-19 on medical education. Cureus 12:e7492

3. Rose S. Medical student education in the time of COVID-19. JAMA Published online March 31, 2020. https://doi.org/10.1001/jama. 2020.5227
4. Scagnoli NI, Choo J, Tian J (2019) Students' insights on the use of video lectures in online classes. Br J Educ Technol 50:399-414

5. Franchi T (2020) The impact of the Covid-19 pandemic on current anatomy education and future careers: a student's perspective. Anat Sci Educ 13:312-315. https://doi.org/10.1002/ase.1966

Publisher's Note Springer Nature remains neutral with regard to jurisdictional claims in published maps and institutional affiliations. 